\title{
Action de LH sur la sécrétion d'œstradiol par l'ovaire embryonnaire de Poulet en culture in vitro
}

\author{
J.-P. WENIGER, J. CHOURAQUI
}

Laboratoire de Zoologie et d'Embryologie expérimentale, Université Louis-Pasteur,

12, rue de I'Université, 67000 Strasbourg, France.

Summary. Effect of $L H$ on oestradiol secretion by the chick embryo ovary in organ culture.

Gonads from 7-to 18-day-old female chick embryos were cultured in vitro in the presence or in the absence of bovine $\mathrm{LH}$, and the amount of oestradiol released into the culture medium was determined by radioimmunoassay. Depending on the stage investigated, one ovary secreted 2.8-28 ng oestradiol during a 24-h culture. LH stimulated oestradiol secretion at all stages studied. The stimulation coefficient was highest for the younger stages. The lowest concentration which gave a positive result was $10 \mathrm{ng} / \mathrm{ml}$. The discrepancy between the strong action of $\mathrm{LH}$ in vitro and its apparent absence of action in normal development is discussed.

\section{Introduction.}

L'action de LH (hCG) sur la sécrétion d'œstradiol par les gonades embryonnaires de Poulet a déjà fait l'objet d'un certain nombre de travaux. Woods et al. (1981) trouvent dans le plasma d'embryons de Poulet de 7,5-9,5 jours d'incubation, mâles aussi bien que femelles, des concentrations doubles d'œstradiol après traitement par LH. En culture in vitro, la production d'œestradiol par les gonades femelles de 18 jours est nettement plus importante en présence qu'en l'absence d'hCG (Guichard et al., 1979). La gonadotrophine chorionique, aussi bien que LH, stimulent la synthèse d'œstradiol à partir d'acétate de $\mathrm{Na}-{ }^{14} \mathrm{C}$ par les gonades femelles de 10 et 18 jours (Cédard et al., 1968; Akram et Weniger, 1974). II nous a paru intéressant d'étendre ces résultats obtenus en culture in vitro à des stades plus jeunes. Le présent travail concerne donc l'action de LH sur la sécrétion d'œstradiol par les gonades femelles d'embryon de Poulet en culture in vitro entre les stades de 7 et 18 jours d'incubation.

\section{Matériel et méthode.}

Les embryons de Poulet utilisés étaient de race Leghorn blanche et avaient entre 7 et 18 jours d'incubation. 
Culture d'organes. - Les gonades furent prélevées sur les embryons femelles, les deux gonades aux stades de 7,8 et 10 jours, seul l'ovaire gauche aux stades de 13 et 18 jours. Elles furent découpées en fragments d'1-2 mm de côté qui furent cultivés dans le milieu 199 pendant $16 \mathrm{~h}$ à $37^{\circ} \mathrm{C}$ dans une atmosphère enrichie en $\mathrm{O}_{2}$ et en $\mathrm{CO}_{2}$. Des testicules furent cultivés comme témoins, ainsi que des fragments de mésonéphros d'un volume total équivalent à celui des gonades femelles. Remarquons que le stade atteint par les embryons après 7 ou 8 jours d'incubation pouvant varier dans de larges limites, nous avons veillé à travailler sur des embryons de stade uniforme, stade 31 de Hamburger et Hamilton (1951) pour les embryons de 7 jours et stade 34 pour ceux de 8 jours.

Le volume de milieu de culture était de $0,7 \mathrm{ml}$ par boîte de Pétri. Le nombre de gonades cultivées par boîte variait de 3 paires à 7 jours à un seul ovaire gauche ou une paire de testicules à 18 jours. Au terme des $16 \mathrm{~h}$ de culture, les explants furent rincés soigneusement avec le milieu et celui-ci fut conservé à $-20^{\circ} \mathrm{C}$ jusqu'au moment du dosage de l'œstradiol. Seul l'œstradiol a été dosé, son taux de sécrétion étant 2-3 fois plus important que celui de l'œstrone (Cédard et al., 1968; Akram et al., 1973 ; Weniger et al., 1983).

L'hormone lutéinisante (NIH-LH-B9 $=1,06 \mathrm{NIH}-\mathrm{LH}-\mathrm{S} 1$ unités/mg) était d'origine bovine et provenait du « National Institute of Arthritis, Metabolism and Digestive Diseases ». Les concentrations voulues étaient obtenues par dilutions successives dans le milieu de culture.

Dosage radioimmunologique de l'œestradiol. - Le dosage a été fait en double dans $20 \mu \mathrm{l}$ de milieu de culture. Le traceur radioactif était l'œestradiol tritié. L'antisérum utilisé était dirigé contre l'œstradiol-7-carboxyméthyloxime conjuguée à la sérumalbumine bovine ; sa réaction croisée avec l'œstrone était d'1\%. L'œstradiol non lié fut adsorbé sur charbon-dextran. La quantité minimale d'œstradiol dosable était de $2 \mathrm{pg}$.

Calculs statistiques. - Après vérification de l'égalité des variances, les moyennes ont été comparées à l'aide du test $t$ de Student basé sur de petits échantillons.

\section{Résultats.}

Sauf dans de rares cas où le milieu de culture était infecté, les explants paraissaient macroscopiquement en bonne condition après les 16 heures de culture. L'examen histologique d'un certain nombre d'entre eux confirma ce diagnostic.

Les résultats obtenus sont consignés dans les 2 tableaux. Il s'agit des résultats bruts, c'est-à-dire des quantités d'œestradiol trouvées dans $20 \mu \mathrm{l}$ de milieu de culture.

Dans la première série expérimentale, nous avons utilisé LH à la concentration d'1 $\mu \mathrm{g} / \mathrm{ml}$. Le coefficient de stimulation de la sécrétion d'œstradiol par les gonades femelles était respectivement de 2,3,6, 4,3 et 6 à 18,13,10 et 8 jours d'incubation (tabl. 1). La stimulation est donc d'autant plus intense que le stade 
est plus jeune. Les quantités d'œstradiol trouvées dans les milieux de culture de testicules et de mésonéphros, en l'absence aussi bien qu'en présence de $\mathrm{LH}$, étaient inférieures au seuil de sensibilité du dosage.

TABLEAU 1

Stimulation de la sécrétion d'œestradiol par $1 \mu \mathrm{g} / \mathrm{m} /$ de $\mathrm{LH}$.

\begin{tabular}{|c|c|c|}
\hline & sans LH & $1 \mu \mathrm{g} / \mathrm{ml} \mathrm{LH}$ \\
\hline 1 ov. g. $18 j$ & $81 \pm 7.7(4)$ & $\begin{array}{c}160 \pm 14(2) \\
\times 2\end{array}$ \\
\hline 1 ov. g. $13 \mathrm{j}$. & $60 \pm 13,7(6)$ & $\begin{array}{c}215 \pm 23(3) \\
\times 3,6\end{array}$ \\
\hline 3 p. gon. $10 \mathrm{j}$ & $70 \pm 18,9(4)$ & $\begin{array}{c}304 \pm 26(5) \\
\times 4,3\end{array}$ \\
\hline 3 p. gon. $8 \mathrm{j}$ & $45 \pm 5,9(5)$ & $\begin{array}{c}270 \pm 14(2) \\
\times 6\end{array}$ \\
\hline
\end{tabular}

Quantités d'œestradiol, exprimées en pg, dans $20 \mu \mathrm{l}$ de milieu de culture. Les moyennes sont accompagnées de l'écart-type. Entre parenthèses, le nombre de cas. Le coefficient de stimulation $(x)$ est déterminé par rapport à la sécrétion d'œstradiol en l'absence de LH.

Puisque les gonades femelles se montrent d'autant plus sensibles à l'action de LH qu'elles sont plus jeunes, nous avons testé des concentrations de 100,10 et $1 \mathrm{ng} / \mathrm{ml}$ de LH aux stades de 7 et 8 jours d'incubation. La concentration de 1 $\mathrm{ng} / \mathrm{ml}$ de LH semble sans effet, mais celle de $10 \mathrm{ng} / \mathrm{ml}$ détermine une augmentation significative de la sécrétion d'œstradiol (tabl. 2).

TABLEAU 2

Stimulation de la sécrétion d'oestradiol par des concentrations décroissantes de $L H$.

\begin{tabular}{lcccc}
\hline & sans LH & $100 \mathrm{ng} / \mathrm{ml} \mathrm{LH}$ & $10 \mathrm{ng} / \mathrm{ml} \mathrm{LH}$ & $1 \mathrm{ng} / \mathrm{ml} \mathrm{LH}$ \\
\hline 3 p. gon. $8 \mathrm{j}$. & $45 \pm 5,9(5)$ & $\begin{array}{l}165 \pm 31(4) \\
\times 3,7\end{array}$ & $\begin{array}{c}54 \pm 2,9(3) \\
\times 1,21 ; \mathrm{P}=0,05\end{array}$ & $\begin{array}{l}42 \pm 5,6(6) \\
\times 0,93 ; \mathrm{N} . \mathrm{S}\end{array}$ \\
\hline 3 p. gon. 7 j. & $26 \pm 5,8(14)$ & $\begin{array}{l}118 \pm 10,6(2) \\
\times 4,6\end{array}$ & $\begin{array}{l}40 \pm 7,3(10) \\
\times 1,5 ; \mathrm{P}<0,001\end{array}$ & $\begin{array}{l}27 \pm 2,5(4) \\
\times 1,06 ; \mathrm{N} . \mathrm{S} .\end{array}$ \\
\hline
\end{tabular}

Quantités d'œstradiol, exprimées en pg, dans $20 \mu \mathrm{l}$ de milieu de culture. Les moyennes sont accompagnées de l'écart-type. Entre parenthèses, le nombre de cas. Le coefficient de stimulation $(x)$ est déterminé par rapport à la sécrétion d'œstradiol en l'absence de LH. P indique le degré de signification de la différence entre les moyennes comparées, l'une des moyennes étant toujours la quantité d'œstradiol sécrétée en l'absence de LH. N.S. : différence non significative. 


\section{Discussion.}

Le présent travail confirme les résultats obtenus antérieurement par Cédard et al. (1968), Akram et Weniger (1974) et Guichard el al. (1979) aux stades de 10 et 18 jours. II établit en outre que dès le stade de 7 jours d'incubation (stade 31 de Hamburger et Hamilton) les gonades d'embryon de Poulet femelles répondent par une sécrétion accrue d'œstradiol au traitement par $\mathrm{LH}$ en culture in vitro, la concentration efficace la plus faible étant de l'ordre de $10 \mathrm{ng} / \mathrm{ml}$. Ces résultats suggèrent l'existence dans les gonades femelles de récepteurs de $\mathrm{LH}$ dès le stade de 7 jours. La stimulation de la synthèse d'œstradiol par LH étant d'autant plus intense que les gonades sont plus jeunes, on peut penser soit que le nombre de récepteurs par cellule sécrétrice d'œstradiol diminue avec l'âge, soit que leur degré d'occupation augmente. Cette dernière éventualité n'est pas une pure fiction, des cellules immunoréactives vis-à-vis d'un antisérum anti-LH étant présentes dans la poche de Rathke dès le stade de 4 jours (Gasc et Sar, 1981) et LH étant décelable dans le plasma dès le stade de 10 jours (Tanabe et al., 1986). Cependant, si LH influait sur la sécrétion d'œestradiol dans les conditions normales, celle-ci devrait diminuer après hypophysectomie. Or, tel n'est pas le cas (Weniger et Zeis, 1987). On peut admettre que la concentration plasmatique de LH reste trop faible pour influer d'une manière sensible sur la sécrétion d'œestradiol ou que l'induction de la synthèse de récepteurs de $\mathrm{LH}$ sous l'influence de $\mathrm{LH}$ exogène est plus forte aux stades jeunes qu'aux stades plus avancés. Quoi qu'il en soit, on est en présence de deux ordres de faits difficiles à concilier, l'action indiscutable de LH in vitro d'une part, son action apparemment nulle dans les conditions du développement normal d'autre part. La solution du dilemme résidera vraisemblablement dans la caractérisation des récepteurs de LH. SignaIons qu'au cours du développement de l'embryon de Rat, l'action de LH sur la sécrétion de testostérone par le testicule apparaît conjointement avec les récepteurs de LH (Gangnerau e/ al., 1982).

Reçu en mars 1988 Accepté en juillet 1988.

\section{Références}

AKRAM H., WENIGER J.-P., 1974. L'hypophyse est sans influence sur la synthèse d'œstrogènes chez l'embryon de Poulet. C.R. Acad. Sci. Paris, Sér. D, 278, 2669-2670.

AKRAM H., ZEIS A., WENIGER J.-P., 1973. Biosynthèse d'œstrogènes par l'ovaire de l'embryon de Poulet hypophysectomisé : aspect quantitatif. C.R. Acad. Sci. Paris, Sér. D, 276, 359-361.

CÉDARD L., HAFFEN K., GUICHARD A., 1968. Influence de l'hormone gonadotrope chorionique sur la production d'œestrogènes à partir d'acétate de $\mathrm{Na}$ et de déhydroépiandrostérone radioactifs par les gonades embryonnaires de Poulet cultivées in vitro. C.R. Acad. Sci. Paris, Sér. D, 267, 118-120.

GANGNERAU M.-N., FUNKENSTEIN B., PICON R., 1982. LH/hCG receptors and stimulation of testosterone biosynthesis in the rat testis changes during foetal development in vivo and in vitro. Mol. cell. Endocrin., 28, 499-512.

GASC J.-M., SAR M., 1981. Appearance of LH-immunoreactive cells in the Rathke's pouch of the chicken embryo. Differentiation, 20, 77-80. 
GUICHARD A., HAFFEN K., CEDARD L., MIGNOT Th-M., SCHEIB D., 1979. Effects of hCG and of season on in vitro steroidogenesis by 18-day chick embryo gonads. Ann. Biol. anim. Bioch. Biophys., 19, 1317-1325.

HAMBURGER V., HAMILTON H. L., 1951. A series of normal stages in the development of the chick embryo. J. Morph, 88, 49-92.

TANABE Y., SAITO N., NAKAMURA T., 1986. Ontogenetic steroidogenesis by testes, ovary, and adrenals of embryonic and postembryonic chickens (Gallus domesticus). Gen. comp. Endocrinol., 63, 456-463.

WENIGER J.-P., CHOURAQUI J., ZEIS A., 1983. Synthèse d'œstrogènes par l'ovaire embryonnaire de Poulet à partir de divers précurseurs radioactifs : comparaison des taux de synthèse. Reprod. Nutr. Dévelop., 23, 995-1002.

WENIGER J.-P., ZEIS A., 1987. 17\%-estradiol secretion by the ovary of the hypophysectomized chick embryo. Gen. comp. Endocrinol., 65, 9-11.

WOODS J.E., MENNELLA J.A., THOMMES R. C., 1981. The hypothalamic-adenohypophyseal-gonadal axes in the developing chick embryo. I. LH sensitivity. Gen. comp. Endocrinol., 45, 66-73. 